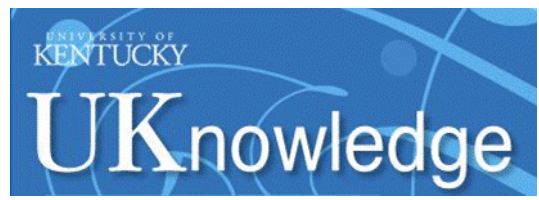

University of Kentucky

UKnowledge

\title{
Measurement and Estimation of the Equivalent Circuit Parameters for Multi-MW Battery Systems
}

\author{
Oluwaseun M. Akeyo \\ University of Kentucky, ochichikeyo@gmail.com \\ Vandana Rallabandi \\ University of Kentucky, vandana.rallabandi@uky.edu \\ Nicholas Jewell \\ LG\&E and $K U$
}

Dan M. Ionel

University of Kentucky, dan.ionel@uky.edu

Follow this and additional works at: https://uknowledge.uky.edu/peik_facpub

Part of the Power and Energy Commons

Right click to open a feedback form in a new tab to let us know how this document benefits you.

\section{Repository Citation}

Akeyo, Oluwaseun M.; Rallabandi, Vandana; Jewell, Nicholas; and lonel, Dan M., "Measurement and Estimation of the Equivalent Circuit Parameters for Multi-MW Battery Systems" (2019). Power and Energy Institute of Kentucky Faculty Publications. 12.

https://uknowledge.uky.edu/peik_facpub/12

This Conference Proceeding is brought to you for free and open access by the Power and Energy Institute of Kentucky at UKnowledge. It has been accepted for inclusion in Power and Energy Institute of Kentucky Faculty Publications by an authorized administrator of UKnowledge. For more information, please contact UKnowledge@lsv.uky.edu. 


\title{
Measurement and Estimation of the Equivalent Circuit Parameters for Multi-MW Battery Systems
}

\author{
Digital Object Identifier (DOI) \\ https://doi.org/10.1109/ECCE.2019.8912233
}

\section{Notes/Citation Information}

Published in 2019 IEEE Energy Conversion Congress and Exposition (ECCE).

(C) 2019 IEEE Copyright Notice. "Personal use of this material is permitted. Permission from IEEE must beobtained for all other uses, in any current or future media, including reprinting/republishing this material for advertising or promotional purposes, creating new collective works, forresale or redistribution to servers or lists, or reuse of any copyrighted component of this work in other works."

The document available for download is the authors' manuscript version that is accepted for publication. The final published version is copyrighted by IEEE and available as: O. M. Akeyo, V. Rallabandi, N. Jewell and D. M. Ionel,"Measurement and Estimation of the Equivalent Circuit Parameters for Multi-MW Battery Systems," 2019 IEEE Energy Conversion Congress and Exposition (ECCE), Baltimore,MD, USA, 2019, pp. 2499-2504, doi: 10.1109/ECCE.2019.8912233. 


\title{
Measurement and Estimation of the Equivalent Circuit Parameters for Multi-MW Battery Systems
}

\author{
Oluwaseun M. Akeyo ${ }^{1}$, Vandana Rallabandi ${ }^{1 *}$, Nicholas Jewell ${ }^{2}$, and Dan M. Ionel ${ }^{1}$ \\ ${ }^{1}$ SPARK Lab, ECE Department, University of Kentucky, Lexington, KY, USA \\ m.akeyo@uky.edu, vandana.rallabandi@ieee.org, dan.ionel@ieee.org \\ ${ }^{2}$ Louisville Gas and Electric and Kentucky Utilities, Louisville, KY, USA \\ nicholas.jewell@1ge-ku.com
}

\begin{abstract}
This paper proposes and validates through simulations and measurements, a procedure for the determining the equivalent circuit parameters of large utility-scale batteries. It is considered that a large battery includes multiple cells connected in series and parallel, and therefore, its equivalent circuit can be represented as a series-parallel network of state of charge (SOC) dependent resistors and capacitors. Tests for determining these equivalent circuit parameters are proposed. These tests involve subjecting the battery energy storage system (BESS) to multiple charge and discharge cycles, while monitoring the terminal voltage and current response. A method for postprocessing and analyzing the measurements in order to obtain an equivalent circuit model that accounts for the dynamic properties of the battery system and differences between the parameters of each cell is developed. The measurements and simulations are conducted for a $1 \mathrm{MW} / 2 \mathrm{MWh}$ BESS demonstrator located at the Louisville Gas and Electric and Kentucky Utilities (LG\&E and KU) E.W. Brown generating plant.
\end{abstract}

Index Terms-PV, battery, MPPT, grid connected inverter, dcdc converter, charge controller, energy storage.

\section{INTRODUCTION}

According to the U.S. Energy Information Administration (EIA), as of the end of 2017 , in excess of $700 \mathrm{MW}$ power and $850 \mathrm{MWh}$ energy capacity utility-scale battery energy storage systems are in operation in the U.S. [1]. A substantial percentage of the multi-MW battery systems are deployed for renewable energy sources support, while also performing multiple ancillary functions such as energy arbitrage, demand response, frequency response, power smoothing, and improving system stability.

Recent studies have focused on the small-scale battery modeling with greater emphasis on single cell operations [2]-[4]. Other researchers have worked towards developing standardized procedures for the estimation of the parameters of a single cell. [5]-[8]. The ability to develop an equivalent circuit model for utility-scale battery systems is becoming increasingly critical due to the growing number of MultiMW battery energy storage system (BESS) installations. The modeling of batteries can facilitate the effective planning and

\footnotetext{
* Dr. Vandana Rallabandi was with the SPARK Laboratory, ECE Department, University of Kentucky, Lexington, KY and is now with GE Research, Niskayuna, NY.
}

scheduling of utility-scale BESS and help identify irregular battery operations.

The conventional method for characterizing large scale battery systems relies on the estimated parameters for one of its cells, which are scaled to represent the behavior of the entire unit [9], [10]. The limitation of this approach is that the chemical variations between the cells within the system and the effects of interconnecting multiple cells are ignored. In this regard, this paper proposes tests to be conducted as well as methods for developing an equivalent circuit model for utilityscale battery systems from the test data. The newly proposed procedure accounts, which is based on tests performed on a large BESS, therefore accounts for the behavior of each cell within the battery. The proposed procedure for parameter estimation benefits from measurements of the type recommended by the new EPRI energy test manual [11], and may also serve as an extension to the EPRI initiative.

The simplified tests and measurements proposed in this paper rely on using equipment typically present in utility-scale BESS installations. In this approach, the BESS is subjected to defined charge/discharge cycles and the dc terminal voltage response is measured, based upon which the parameters of the unit corresponding to specified SOC levels are determined. A runtime equivalent battery system model is then developed and validated over three cases with experimental results retrieved from measurements conducted on a $1 \mathrm{MW} / 2 \mathrm{MWh}$ BESS located at the LG\&E and KU E.W. Brown generating plant.

\section{EXPERIMENTAL FACILITIES}

A typical standalone utility-scale BESS includes a battery rack system with multiple cells connected to the dc-link of a bidirectional dc to ac power conversion system (PCS) and a transformer for voltage matching, electrical isolation and grid interconnection. The E.W. Brown facility battery demonstrator includes a 2MWh battery system, a 1MVA bidirectional PCS, a $13.2 \mathrm{kV} / 480 \mathrm{~V}$ step-up transformer and a 1MVA programmable load bank (Fig. 1). Voltage, current and power measurements at the dc-link, inverter ac terminal, and the point of common coupling are synchronized with the local time and logged at one second intervals by the SCADA system. 


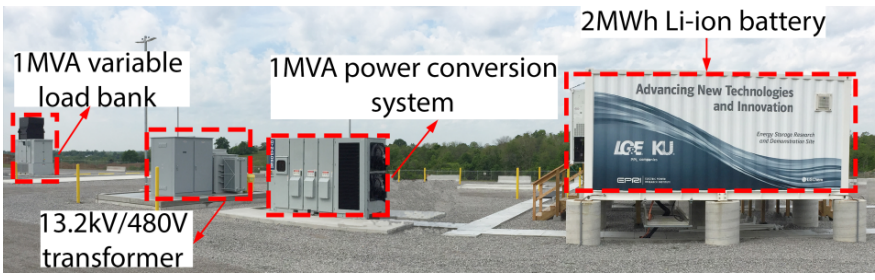

Fig. 1. The $1 \mathrm{MW} / 2 \mathrm{MWh}$ battery demonstrator unit installed at the LG\&E and KU E.W. Brown universal solar facility as a joint project with EPRI employed for this study.

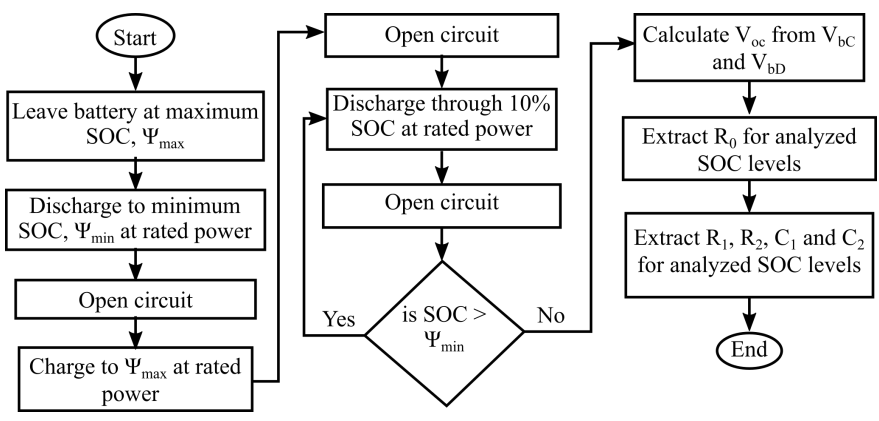

Fig. 2. Flowchart for the experimental procedures employed in the proposed parameter extraction. The battery system is open-circuited or kept in the float mode in between tests in order to ensure chemical equilibrium among all cells.

In order to meet the ratings of the power conditioning device, the experimental battery system includes 20 racks, which are equally distributed between two identical containers. A rack includes 17 LG Chem M48126P3B1 battery modules, each with $14 \mathrm{Li}$-ion cells and rated for $126 \mathrm{Ah}$ at $51.8 \mathrm{~V}$ nominal voltage. This battery system also employs a battery management system (BMS), whose function includes the supervision of cell performance and balancing the SOC across all cells. The setup PCS is a 1MVA Dynapower bidirectional two-level converter, which may be operated at $740-1150 \mathrm{~V}$ dc-link voltage, while maintaining a constant $480 \mathrm{~V}$ on the ac side. For the purpose of carrying out multiple discharge tests with reduced grid disturbance and enable BESS operation in the isolated mode, the system is equipped with a 1MVA, $480 \mathrm{~V}$ three-phase simplex programmable large size load bank, which is capable of absorbing up to $1 \mathrm{MW}$ resistive power and sourcing/absorbing reactive power up to $600 \mathrm{kVAr}$ at $5 \mathrm{kVA}$ load steps (Fig. 1).

\section{Proposed Test Procedures for the Battery SYSTEM}

The parameters of a battery cell vary with different factors including, temperature, state of health, state of life, depth of discharge, and SOC. Cells within a large battery system have unique characteristics and parameters even if they are identical models from the same manufacturer. Furthermore, in large multi-MW BESS, the cells are subjected to different operational conditions and loads due to the presence of the battery management system (BMS), which is employed for protection, monitoring and SOC balance across all cells.

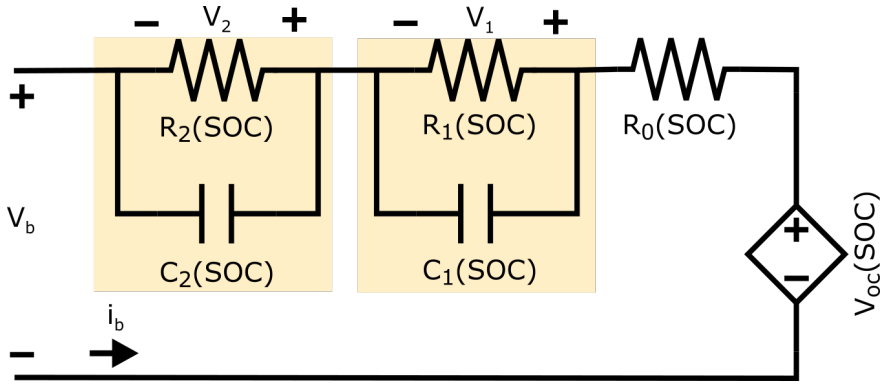

Fig. 3. Example equivalent circuit diagram for a battery system, in which each parameter corresponds to the combination of all cells connected in series and parallel.

Hence, for the purpose of modeling a large battery, simply scaling the equivalent circuit parameters of a single cell may not be sufficient to represent the system dynamics.

In order to develop an equivalent battery system circuit that captures the dynamics of having multiple cells connected in series and parallel and a unit that employs an operational BMS, the proposed approach regards the entire battery system as a single cell whose equivalent circuit parameters captures the dynamics of all the connected cells.

The experimental BESS system setup was subjected to multiple charge and discharge cycles and its responses including the measured battery terminal voltage and current, the BMS computed SOC, and the PCS real and reactive power were recorded. For this example utility-scale battery system, the recommended minimum and maximum SOC limits from the manufacturer are $5 \%$ and $95 \%$, respectively.

At the time of this research, a standard time for utility-scale battery system to reach equilibrium had not been described. Hence, a rest period of $8 \mathrm{~h}$ before tests and $2 \mathrm{~h}$ after each pulse operation is proposed for the battery system based on voltage response observations.

The sequence of testing begins with the open-circuit voltage estimation. The temperature of the battery rack system, which is placed in an enclosed chamber was fixed at $23^{\circ} \mathrm{C}$ throughout this study in order to ensure minimum temperature error. The battery is charged to the maximum SOC recommended by its manufacturer and kept in the float mode for 8 hours. The float mode operation enables the battery system to approach chemical equilibrium while maintaining it at reference SOC by trickle charging at a rate equal to its self-discharge. It is then continuously discharged at the rated power until the manufacturer recommended minimum SOC is reached. After operation in the float mode for another 8 hours, its then charged back to the maximum SOC (Fig. 2). Similar to [12], the open circuit voltage $\left(v_{o c}\right)$ variation with respect to SOC was defined as the average terminal voltage variation during charge $\left(v_{b C}\right)$ and discharge $\left(v_{b D}\right)$ illustrated in Fig. 4a.

In the second test, the battery is again initialized by charging it to the maximum SOC and operating in float mode for 8 hours. In order to capture both transient and steady-state responses of the battery rack system, the BESS system was pulse discharged at rated power. After initialization, the BESS 


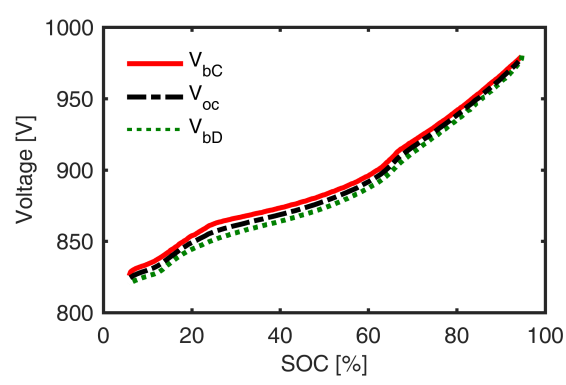

(a)

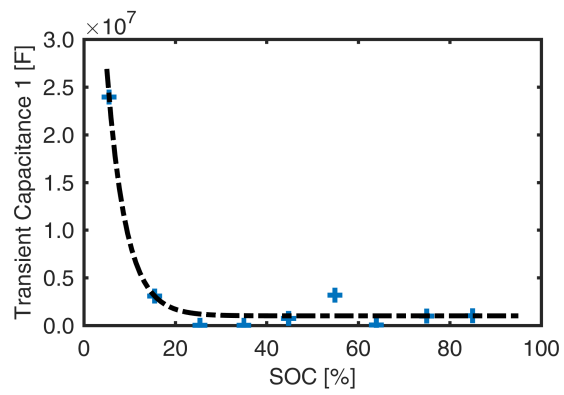

(d)

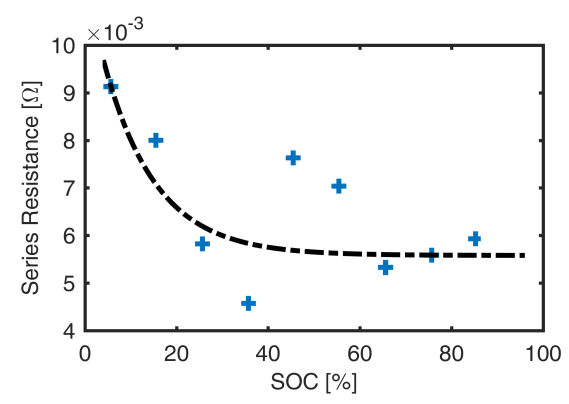

(b)

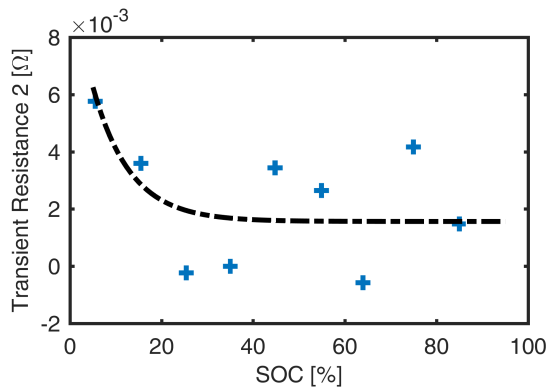

(e)

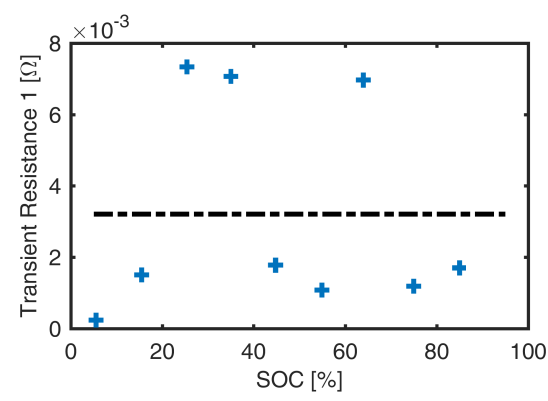

(c)

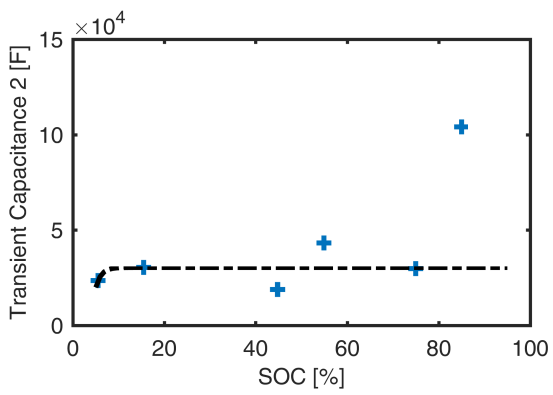

(f)

Fig. 4. Battery system equivalent circuit parameters. The battery terminal voltage and SOC relationship during continuous charge and discharge is interpolated to estimate its open-circuit voltage, while the series resistance and RC branch components are estimated through analysis of the terminal voltage during pulse discharge. Open circuit voltage (a), series resistance (b), transient resistance 1 (c), transient capacitance 1 (d), transient resistance 2 (e), transient capacitance 2 (f).

was continuously discharged at rated power through $10 \%$ SOC and operated in the float mode for 2 hours in order to allow the battery system to approach equilibrium. The $10 \%$ pulse discharge procedure was repeated until the system SOC reached the minimum. Conventional approaches require pulse discharging the battery cell at constant current. The proposed procedure is adapted to the equipment typically available at a utility scale BESS, and therefore, the PCS is controlled for pulse discharging the battery based on a power command.

\section{Extraction of EQuivalent Circuit PARAmeters FOR THE BATTERY SYSTEM}

In this approach, the battery system is described as a controllable voltage source connected in series to a resistance $\left(R_{0}\right)$ and multiple RC branches $\left(R_{1}, R_{2}, C_{1}\right.$ and $\left.C_{2}\right)$, where each parameter represents all the connected cells (Fig. 3). For simplicity, variables such as number of charges cycles and battery state of health are not considered. Hence, the parameters are only represented as a function of SOC. The battery system terminal voltage, $v_{b}$ during discharge may be described as:

$$
v_{b}(t)=v_{o c}-i_{b} R_{0}-v_{1}(t)-v_{2}(t),
$$

where, $v_{o c}$, is the battery open-circuit voltage; $i_{b}$, the battery dc output current; $v_{1}$ and $v_{2}$, the voltages across the RC branches 1 and 2, respectively and $t$, the discharge duration. During the rated power continuous charge and discharge tests, the RC branches capacitors, $C_{1}$ and $C_{2}$ become fully charged and thus, the battery system terminal voltage may be expressed as:

$$
v_{b C}, v_{b D} \Rightarrow v_{o c} \pm i_{b}\left(R_{0}+R_{1}+R_{2}\right),
$$

where, $v_{b C}$ are $v_{b D}$ are the measured terminal voltages during charge and discharge, respectively. Hence, $v_{o c}$ as a function of SOC was estimated as the average value of $v_{b C}$ and $v_{b D}$ at the corresponding SOCs. Since the BESS was continuously dispatched at the rated PCS power during these tests, the measured $i_{b}$ increases as $v_{b}$ decreases due to reduction in SOC, leading to significant difference between $v_{b C}$ are $v_{b D}$ as the SOC approaches minimum (Fig. 4a).

The measurements during the pulse discharge were used to estimate the value of the passive elements for the battery system equivalent circuit. Based on the voltage-current relationship of a capacitor, during the battery system pulse discharge, it was assumed that,

$$
\left[v_{1}\left(t_{o c}^{-}\right), \quad v_{2}\left(t_{o c}^{-}\right)\right]=\left[v_{1}\left(t_{o c}^{+}\right), \quad v_{2}\left(t_{o c}^{+}\right)\right],
$$

where $t_{o c}^{-}$and $t_{o c}^{+}$are the times just before and after the battery is open circuited for each pulse, respectively. Hence, the voltage transient after each pulse is exclusively credited to $R_{0}$ and expressed as:

$$
R_{0}=\frac{v_{b}\left(t_{o c}^{-}\right)-v_{b}\left(t_{o c}^{+}\right)}{i_{b}\left(t_{o c}^{-}\right)-i_{b}\left(t_{o c}^{+}\right)} .
$$

In this approach, the fairly logistic curve observed in the measured voltage during open-circuit after each pulse discharge was attributed to the exponential decay of the 


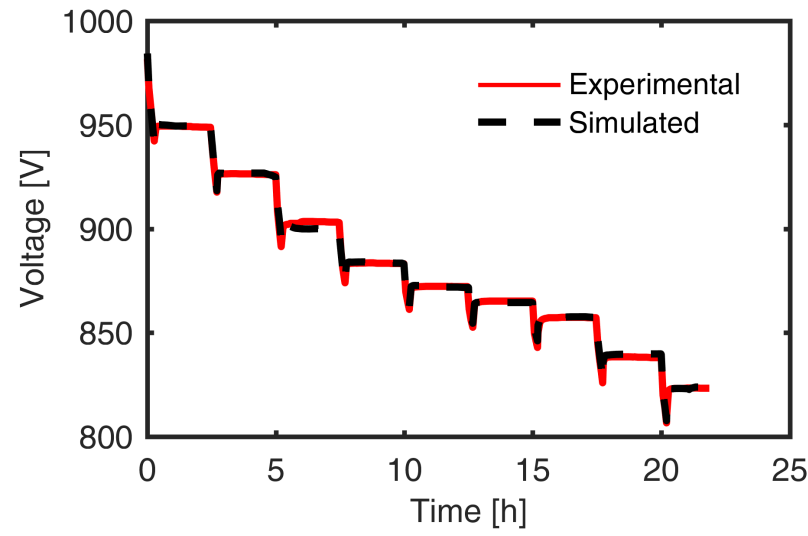

(a)

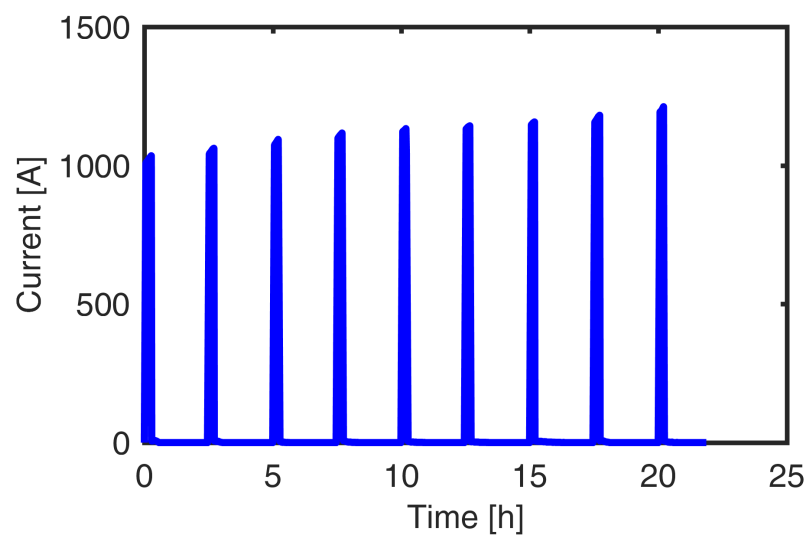

(c)

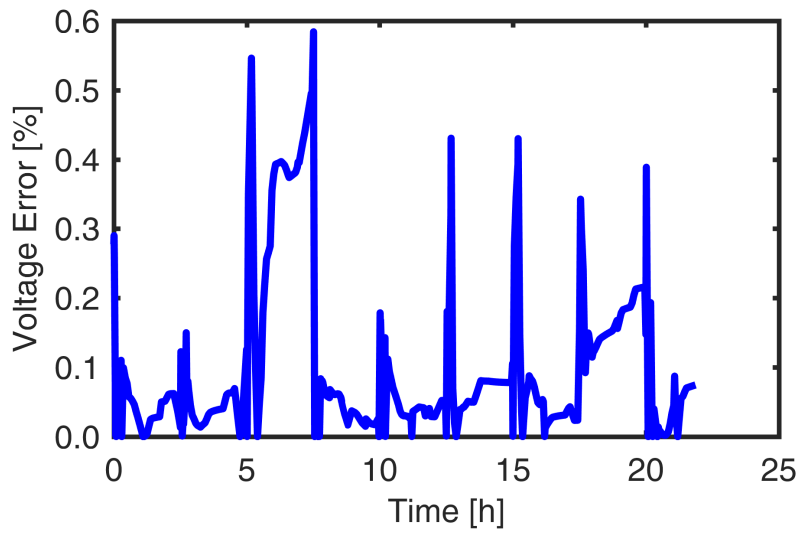

(b)

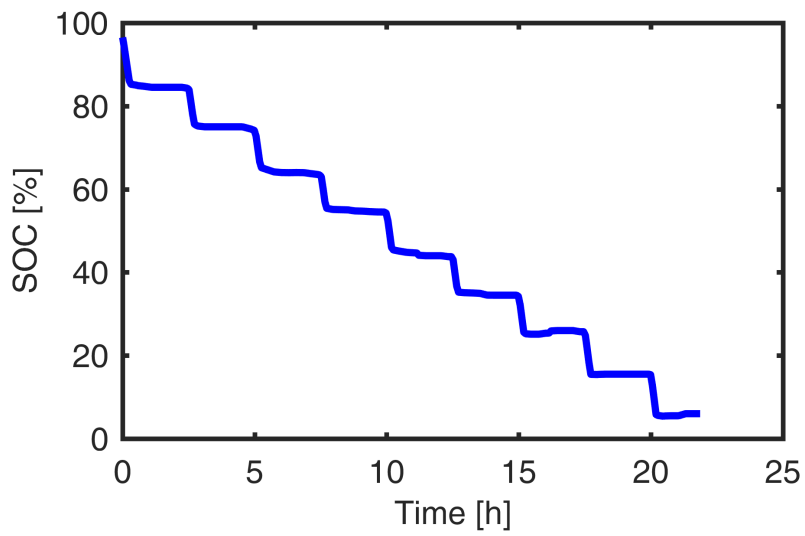

(d)

Fig. 5. The equivalent battery system during rated power pulse discharge from maximum to minimum SOC showing: The experimental and simulated battery system terminal voltage variation (a), the percentage voltage error (b), the discharge current (c), and the SOC variation (d).

voltage across the capacitances. From (1) the capacitor voltage responses after open-circuit may be expressed as:

$$
v_{1}(\Delta t)+v_{2}(\Delta t)=v_{o c}-v_{b}(\Delta t)-i_{b} R_{0}
$$

where, $\Delta t$, is the duration of open-circuit. Since the battery self-discharge over $2 \mathrm{~h}$ may be regarded insignificant in this application, the battery system SOC was assumed to be constant during the open-circuit period. The measured battery voltage from just before the open-circuit to the period when the voltage starts to decay was isolated for each pulse discharge. This portion of the voltage curve is evaluated using (5), and the combined RC branch voltage response may be written as

$$
v_{1}(\Delta t)+v_{2}(\Delta t)=i_{b} R_{1} e^{-\frac{\Delta t}{R_{1} C_{1}}}+i_{b} R_{2} e^{-\frac{\Delta t}{R_{2} C_{2}}} .
$$

The measured $\mathrm{RC}$ branch voltage responses were fitted to (6) in other to estimate the RC parameters related to each SOC. Single variable exponential functions were developed to establish the relationships between the equivalent circuit passive elements and the battery system SOC (Fig. 4).

\section{EXPERIMENTAL VALIDATION}

The proposed battery system was validated over three BESS cycles with all results presented at the resolution of one second. The first test involves comparing the terminal voltage response of the equivalent circuit with experimental results, from which its parameters were developed. A maximum of $0.6 \%$ voltage error calculated as a percentage of the experimental voltage was realized at approximately $55 \%$ SOC. This error may be due to the battery system SOC variation while the PCS is connected in float mode. The peak voltage error is observed during the connected load transient, and it may be noted that the battery system dc output current increases with reduction in its voltage in order to continue pulse discharging at rated power as SOC diminishes (Fig. 5).

The equivalent battery system circuit was also validated over continuous and diverse deep charge/discharge cycles. The BESS was subjected to one of the example test cycles described in the EPRI energy test manual, where it was discharged from maximum to $50 \%$ SOC, charged to maximum and then discharged to minimum SOC level at the rated power. This procedure was then repeated at $75 \%$ rated power and the results show sufficient correlation between the experimental and simulated voltage responses, demonstrating the accuracy of the battery system equivalent circuit over different initial SOC levels (Fig. 6). 


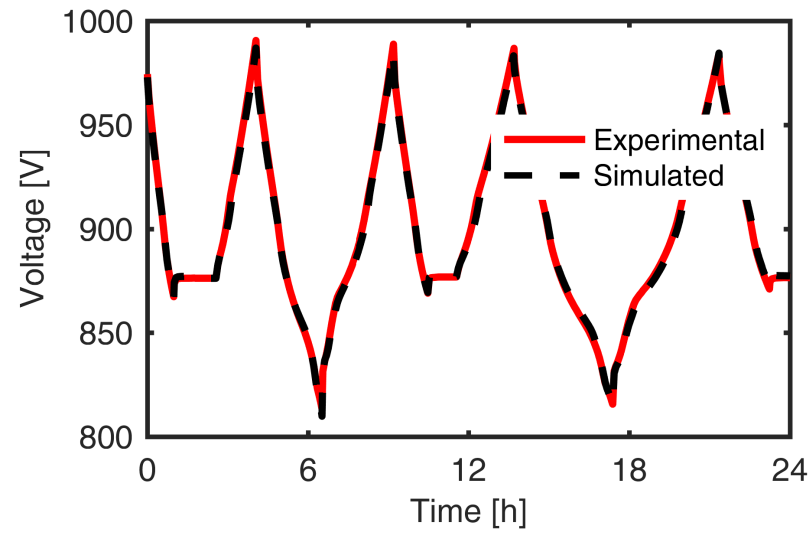

(a)

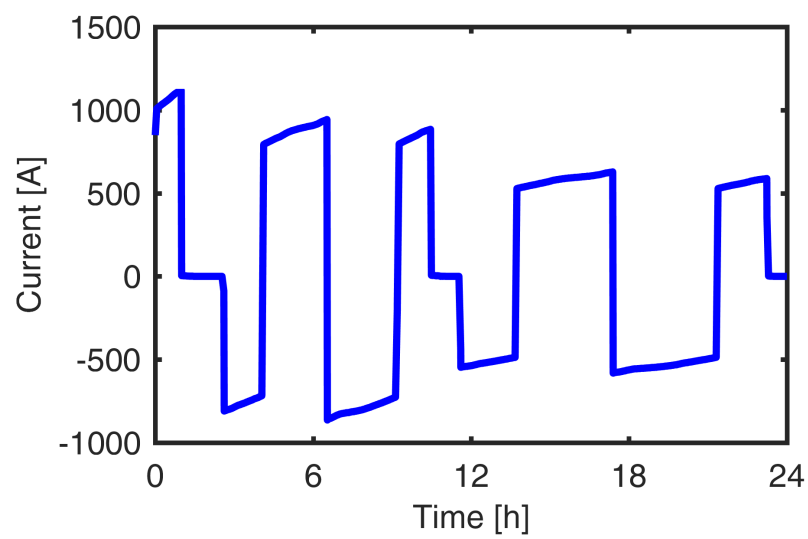

(c)

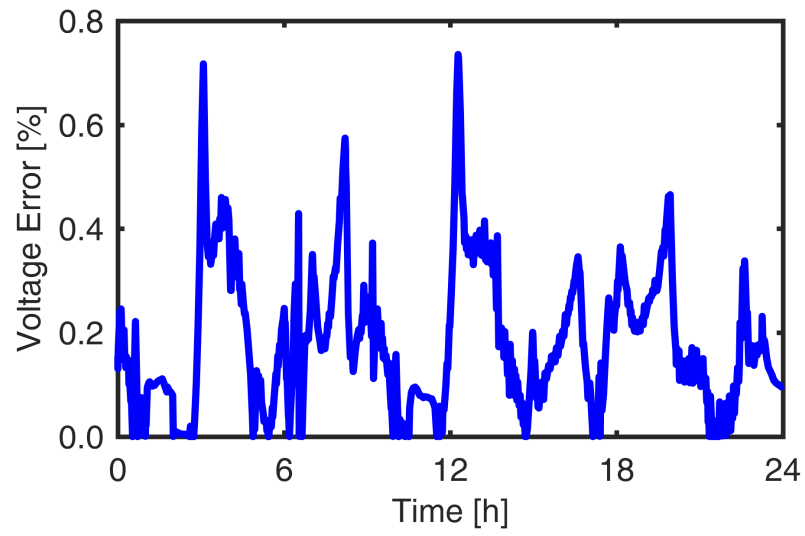

(b)

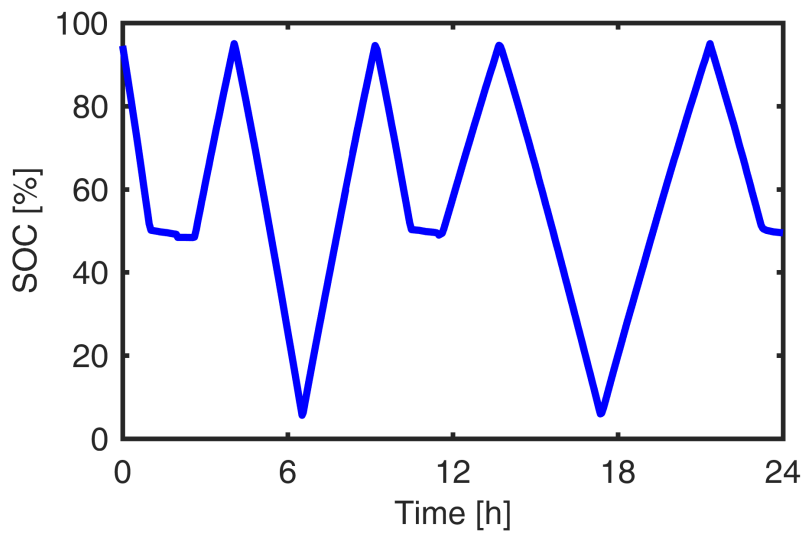

(d)

Fig. 6. The battery system during dynamic charge and discharge between multiple SOC level at rated and 75\% power showing the: Experimental and simulated battery system voltage variation (a), percentage voltage error (b), charge current (c), and SOC variation (d).

Battery energy storage systems may be employed for frequency response, where they are subjected to charge and discharge operations in other to maintain the grid frequency at its reference value. In this case, the experimental BESS was operated in automatic frequency response mode with high sensitivity, to allow the BESS respond to frequency deviations greater than $0.005 \mathrm{~Hz}$. The equivalent circuit model was connected to a current source whose output is identical to the measured dc current. The accuracy of the equivalent battery system was established based on the similarity between the experimental and simulation voltage responses (Fig. 7).

\section{CONCLUSION}

This paper proposes tests for determining the equivalent circuit parameters of a multi-MW BESS. These tests rely on equipment already available at utility scale battery installations. Furthermore, an approach to develop an active runtime equivalent circuit model based on the tests is developed. Unlike other traditional methods, which involve scaling the parameters of a single cell, the proposed approach takes realistically into account the chemical variations of the cells within the battery system and the effects of interconnecting and balancing multiple cells.

The accuracy of the developed battery system equivalent circuit was validated over three charge/discharge cycles, in which the simulated results were compared with experimental measurements retrieved from a large scale experimental facility, which includes a 1MW/2MWh BESS demonstrator and 1MVA load. The results illustrate a voltage response with error below $0.8 \%$. The parameter estimation using optimization techniques as well as the establishment of a relationship between the parameters of the constituent battery cells and those of the unit are subjects of ongoing research.

\section{ACKNOWLEDGMENT}

The support of LG\&E and KU, and University of Kentucky, the L. Stanley Pigman endowment, of the SPARK Laboratory, and the Power and Energy Institute of Kentucky (PEIK) is gratefully acknowledged.

\section{REFERENCES}

[1] U.S. Battery Storage Market Trends. U.S. Energy Information Administration, May 2018. 


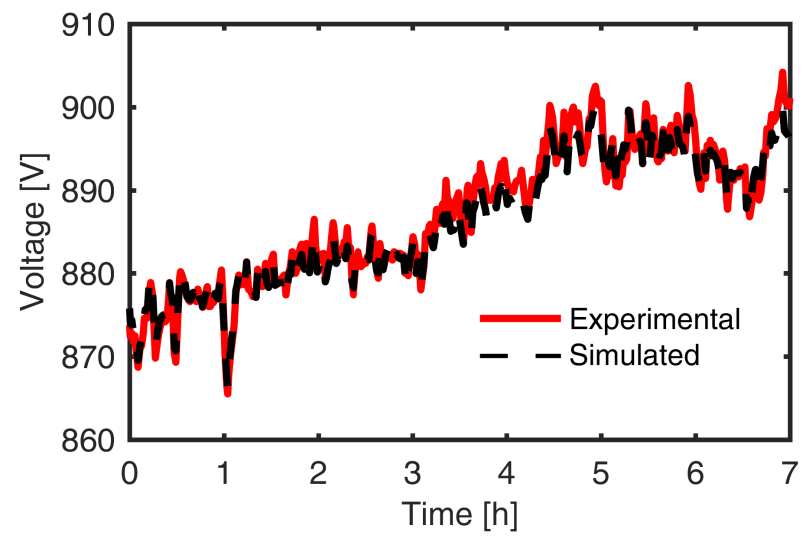

(a)

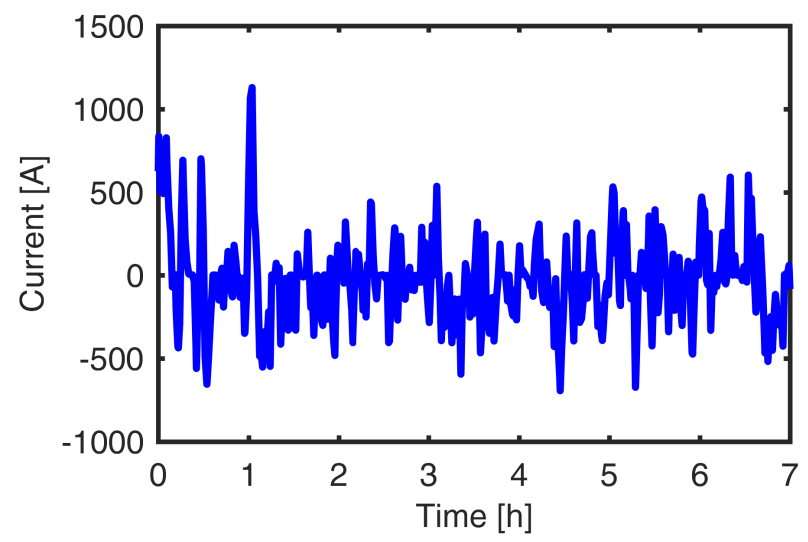

(c)

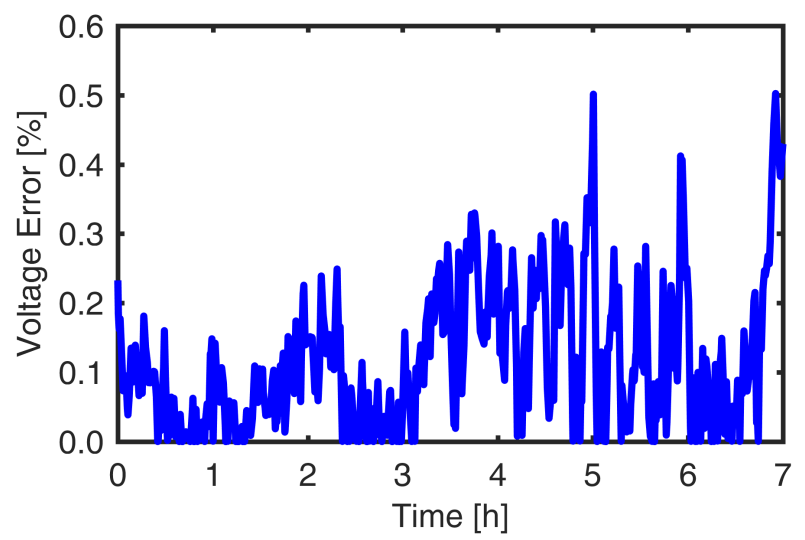

(b)

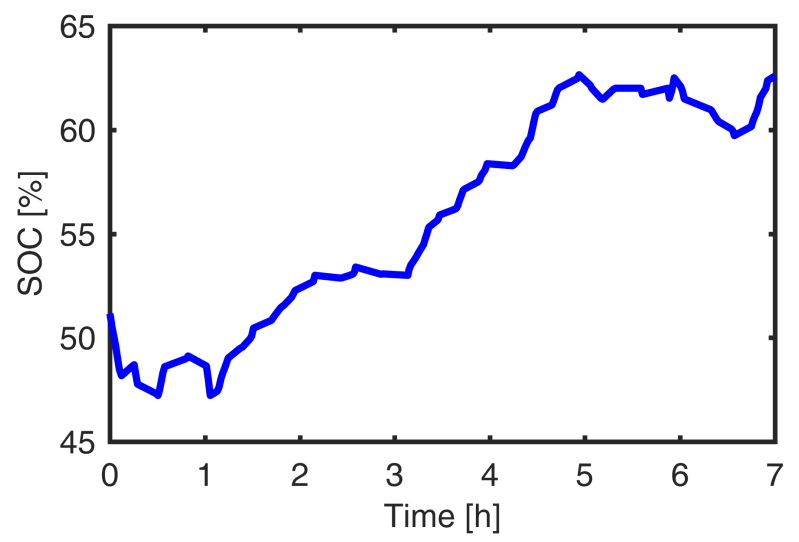

(d)

Fig. 7. The battery system during automated grid frequency response, showing the: Experimental and simulated battery system terminal voltage variation (a), percentage voltage error (b), charge current (c) and SOC variation (d).

[2] D. Dvorak, T. Bäuml, A. Holzinger, and H. Popp, "A comprehensive algorithm for estimating lithium-ion battery parameters from measurements," IEEE Transactions on Sustainable Energy, vol. 9, no. 2, pp. 771-779, April 2018.

[3] C. R. Lashway and O. A. Mohammed, "Adaptive battery management and parameter estimation through physics-based modeling and experimental verification," IEEE Transactions on Transportation Electrification, vol. 2, no. 4, pp. 454-464, Dec 2016.

[4] H. M. Usman, S. Mukhopadhyay, and H. Rehman, "Universal adaptive stabilizer based optimization for li-ion battery model parameters estimation: An experimental study," IEEE Access, vol. 6, pp. 49546-49562, 2018.

[5] S. A. Hamidi, D. M. Ionel, and A. Nasiri, "Batteries and ultracapacitors for electric power systems with renewable energy sources," Renewable Energy Devices and Systems with Simulations in MATLAB ${ }^{\circledR}$ and $A N$ SYS®, 2017.

[6] A. Biswas, R. Gu, P. Kollmeyer, R. Ahmed, and A. Emadi, "Simultaneous state and parameter estimation of li-ion battery with one state hysteresis model using augmented unscented kalman filter," in 2018 IEEE Transportation Electrification Conference and Expo (ITEC), June 2018, pp. 1065-1070.
[7] D. C. Cambron and A. M. Cramer, "A lithium-ion battery current estimation technique using an unknown input observer," IEEE Transactions on Vehicular Technology, vol. 66, no. 8, pp. 6707-6714, Aug 2017.

[8] A. M. Bizeray, J. Kim, S. R. Duncan, and D. A. Howey, "Identifiability and parameter estimation of the single particle lithium-ion battery model," IEEE Transactions on Control Systems Technology, pp. 1-16, 2018.

[9] X. Gong, R. Xiong, and C. C. Mi, "Study of the characteristics of battery packs in electric vehicles with parallel-connected lithium-ion battery cells," IEEE Transactions on Industry Applications, vol. 51, no. 2, pp. 1872-1879, March 2015.

[10] J. Lee, J. Ahn, and B. K. Lee, "A novel li-ion battery pack modeling considerging single cell information and capacity variation," in 2017 IEEE Energy Conversion Congress and Exposition (ECCE), Oct 2017, pp. 5242-5247.

[11] Energy Storage Integration Council (ESIC) Energy Storage Test Manual. EPRI, Palo Alto, CA: 2017. 3002011739.

[12] H. He, R. Xiong, X. Zhang, F. Sun, and J. Fan, "State-of-charge estimation of the lithium-ion battery using an adaptive extended kalman filter based on an improved thevenin model," IEEE Transactions on Vehicular Technology, vol. 60, no. 4, pp. 1461-1469, May 2011. 